\title{
Maná sobre el océano: Los viajes del árbol del pan
}

\author{
Walter Ledermann Dehnhard ${ }^{1}$
}

\section{Manna over the ocean: The breadfruit's voyages}

Ending the nineteenth century the King of England sent Captain Bligh with orders to take from Tahiti to Jamaica plants of the breadfruit tree, searching for a chip and nutritive food for his slaves in the New World. The first voyage failed because the famous Bounty's mutiny; in the second, with the Providence and the Assistance, Bligh did successfully his task and today the tree growths well all around the Caribbean Sea, being not only a popular food, but also, in hands of a good chef, a gourmet's dish.

Key words: Manna, Breadfruit, Bligh, Bounty.

Palabras clave: Maná, Árbol del pan, Bligh, Bounty.

\section{Luchando contra el hambre en el Nuevo Mundo}

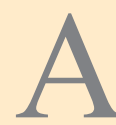
quienes cultivan la historia de la medicina parece atraerles más la narración de las epidemias, fenómenos naturales que afectan a países ricos y pobres, que la tragedia humanitaria implicada en las hambrunas, debidas a causas políticas, económicas y naturales, más silenciosas en su desarrollo, que suelen terminar, tras gran mortalidad, en una persistente desnutrición de la población.

Inglaterra, país previsor, cuyos HMS (His Majesty's Ship), "los buques de Su Majestad", le habían permitido conquistar lejanos territorios, detectaron a tiempo un problema de nutrición en uno de éstos, la isla de Jamaica, donde explotaban impunemente los recursos naturales con mano de obra esclava que buscaban alimentar bien, pero a bajo precio. Al enfrentar este problema no actuaban por razones humanitarias, pues los derechos humanos existían entonces sólo en el pensamiento de algunos santos, sino por razones prácticas, utilitarias y mercantiles, buscando "disminuir los costos". ¿Cómo obtener alimentos baratos pero nutritivos en abundancia? No se trataba de alimentar gourmets, sino gente vil (a su juicio), secuestrada en África y llevada a las colonias. ¿Arroz, carne, harina?... Muy caro. La solución la aportaron los HMS, en uno de los cuales, el Endeavour, el mítico capitán Cook descubrió en sus viajes a los mares del sur, vale decir a la Polinesia, el maná en Tahití en abril de 1769; no, no el maná bíblico, sino el árbol del pan, bueno, barato y bastante.

\section{El maná}

La Real Academia de la Lengua define así el maná: "En el Antiguo Testamento alimento a modo de copos de nieve, que Dios envió a los israelitas para socorrerlos mientras atravesaban el desierto" (tras escapar de la esclavitud en Egipto e iniciar la búsqueda de la Tierra prometida, agregamos nosotros); $y$, en una segunda acepción, "cosa beneficiosa que se recibe sin esfuerzo y en forma inesperada". Según se cuenta en Éxodo, al evaporarse la capa de rocio se vio en la superficie del desierto una cosa menuda y grumosa... y Moisés díjoles "este es el pan que Yahvé os da por alimento" ... y era como granos de cilantro blanco y su sabor como torta de miel... Por su parte, en Números se cuenta que el pueblo solía desparramarse para recogerlo; lo molían en molinos; lo majaban en morteros y lo cocían en ollas o hacían de él tortas, y era su sabor de buñuelos amasados en aceite 2 . Los científicos acusan de producir el maná a diversos hongos, líquenes y árboles; los exegetas han llegado a decir, en forma salomónica, que el sabor dependía del comensal, y si para los niños sabía a miel, para los jóvenes a aceitunas y para los adultos, más parcos, a pan. De todo esto pudiera concluirse que era una fruta o semilla que, molida como harina, permitía hacer pan.

\section{El árbol del pan}

Tras enterarnos de las características supuestas del maná, no dudamos en describir al árbol del pan que Cook encontró en Tahití como un auténtico productor de maná. El Artocarpus (del latín arto = pan y carpus = fruto) altilis (yaca, frutipan, arbopan, ñame isleño, mazapán, pan de pobre, etc), descrito por J.R. Forster y G.A. Forster, padre e hijo, entre 1772 y 1775 a bordo de un HMS, es un árbol originario de la Polinesia, que puede alcanzar una altura de 18 metros y genera un fruto redondo, envuelto por una cáscara verde, de unos 20 centímetros de diámetro,
${ }^{1}$ Centro de Estudios Humanistas Julio Prado.

Recibido: 13 de noviembre de 2019

Correspondencia a: Walter Ledermann Dehnhard oncemayor@gmail.com 
de los cuales puede producir unos 700 cada año (media tonelada), rico en almidón, proteína, ácido fólico, $\mathrm{Ca}, \mathrm{Mg}$, $\mathrm{P}, \mathrm{K}$ y vitaminas $\mathrm{A}, \mathrm{B}, \mathrm{C}$.

En tiempos de nuestra historia constituía un alimento esencial en la dieta de los nativos, quienes lo molían para hacer una harina que cocían obteniendo una pasta similar al pan. Además, la parte interna y fibrosa de su corteza les servía para su vestimenta y la madera para un rudimentario mobiliario. Otras especies del género, como el $A$. heterophyllus (árbol de Jack en América) también producen frutos semejantes, descendiendo todas ellas $\operatorname{del} A$. camansi, originario de las Molucas y Filipinas ${ }^{3,4}$.

\section{William Bligh (1754-1817)}

Al momento de embarcarse en el HMS Bounty tenía 33 años y contaba como antecedentes favorables el haber acompañado al Capitán Cook en su segundo viaje alrededor del mundo durante los años 1772 y 1774, y haber participado en dos batallas navales, en 1781 y 1782 . Habiéndose retirado para dedicarse a la marina mercante, fue llamado de nuevo a la Armada para hacerse cargo del Bounty con el grado de teniente de navío, pues siendo un buque harto pequeño y la finalidad del viaje científica y no bélica, no se requería un capitán, demostrando que siempre, antes y ahora, los hombres valoran más la guerra que la ciencia.

Si bien, como veremos, la empresa del Bounty terminó mal y sin árboles en 1790, un año después Bligh lograría el éxito en su nuevo viaje a cargo del HMS Providence. Más tarde se vería envuelto en otros dos motines: en el primero se mantuvo bravamente de parte de la flota contra los amotinados en 1797, pero en el segundo, siendo un opresivo Gobernador de Nueva Gales del Sur, en Australia, fue depuesto y enviado a Inglaterra en 1810. Aparentemente allí no se le encontró culpable, pues al año siguiente fue ascendido y luego nombrado Vicealmirante, grado con que se retiró definitivamente ${ }^{5}$.

En realidad, parece que el hombre no era más malo ni más cruel que otros capitanes de la época. Si antes de embarcar en el Bounty se robó dos quesos que hizo enviar a casa y que al salir de Tahití arrebatara a sus oficiales regalos recibidos de los nativos, quizás eran hechos habituales en los capitanes. Que era buen marino lo demostró al llevar su bote hasta Timor al ser expulsado del Bounty; que poseía otras habilidades lo señala cómo, a la edad de 15 años, ya fuera versado en ciencia y en matemáticas, además de ser un excelente escritor y un fino dibujante; y como comandara con éxito viajes científicos fue aceptado en la famosa Royal Society como miembro de número tras haber descrito otro árbol polinésico con frutos comestibles, que luego fue llamado Blighia sapida en su honor. Merecía, entonces, ser recordado más allá de la historia del motín 6 .

\section{El primer viaje, en el Bounty}

Como S.M. el rey tuviese la bondad de acceder a la demanda de mercaderes y plantadores de las posesiones de S.M. en las Antillas, interesados en que se procurara aclimatar en aquellas islas el árbol del Pan, se compró un bajel apropiado para tal empresa y fue metido en dique en Depford para dotarlo de los requisitos y preparativos necesarios para realizar el objetivo del viaje.

El objetivo del viaje era una verdadera investigación botánica en terreno, como lo indican estas palabras con que el capitán Bligh inicia el relato de su desventurada travesía, que ya hemos narrado in extenso anteriormente ${ }^{7}$.

Cook había señalado el camino a este trágico navío, cuya penosa historia ha inspirado muchos libros y al menos tres películas: la primera con Clark Gable como el amotinado y Charles Laughton como el capitán en 1935, la segunda con Marlon Brando y Trevor Howard en los mismos papeles en 1962 y la tercera, harto desafortunada, con Mel Gibson y Anthony Hopkins en 1984, pero no hay dónde perderse, la mejor es la más antigua.

El HMS Bounty era un navío más bien pequeño, especialmente adaptado para su extraña tarea, que consistía en recolectar centenares de almácigos del árbol del pan en las Islas de la Sociedad, y llevarlos para plantarlos en las Antillas, proporcionando así un alimento barato y nutritivo a los esclavos locales. Para transportar las macetas, la nave había sido muy bien acondicionada, como lo cuenta el mismo Bligh: El entrepuente estaba dividido de modo que la gran cámara estaba destinada a la conservación de las plantas y se extendía hacia delante hasta la escotilla posterior. Tenía dos anchas claraboyas y, a cada lado, tres portillas para dar paso al aire, y se le habia montado un pavimento de quita y pon, lleno de orificios donde meter las macetas en que se habian de llevar las plantas. La cubierta iba forrada de plomo, y en las esquinas anteriores de la cámara se habian instalado unos tubos, a fin de recoger en cubos colocados debajo el agua que fluyera de los tiestos, para poder volver a utilizarla. Se me ha mandado recibir a bordo a los dos jardineros David Nelson y William Brown, a los que se ha contratado por sus conocimientos de los árboles y plantas, con el fin de que escojan los que les parezcan de las especies y tamaños adecuados.

A instancias de Sir Joseph Banks -especifica Bligh más adelante-se nombró a dos personas peritas y cuidadosas para hacerse cargo de los plantones que se pensaba traer de vuelta: una, David Nelson, que había desempeñado el mismo cargo en el último viaje del capitán Cook; y la otra, William Brown, para servirle de ayudante. En las órdenes del Almirantazgo ambos son mencionados como jardineros y así los anota Bligh en su nómina, pero más tarde, cuando se produce el motín, sus disímiles actuaciones hacen que el capitán comience a mencionar al leal 
Nelson como “botánico”, y de Brown se limite a decir que estuvo al lado de los amotinados; los testigos, durante el juicio, declararán que Brown estaba en cubierta junto a los rebeldes, armado e insultando al capitán.

El Bounty se hizo a la mar el 23 de diciembre de 1787 desde Spithead con destino a las Islas de la Sociedad, que hoy son parte de la Polinesia francesa: Tahití, Bora-Bora y otras playas paradisíacas. Cuatro meses después intentaría doblar el Cabo de Hornos para tomar la ruta corta a Tahití a través del Pacífico, fracasando en el intento por el mal tiempo. Con gran pesar me di cuenta de lo desesperado y aun injustificable que era persistir en intentar dirigirnos desde allí a las islas de la Sociedad-escribe Bligh en su bitácora-. Llevábamos treinta dias en aquel océano borrascoso... Vira entonces hacia la costa de África para pasar bajo el Cabo de Buena Esperanza y tomar la ruta mucho más larga, para alcanzar y rebasar Australia, Nueva Zelandia y las Islas Cook, llegando por fin a Tahití, tras nueve meses de viaje, el 26 de septiembre de 1788.

Habiendo desembarcado, el jefe Tinah lo recibió cariñosamente, haciendo recuerdos del capitán Cook. Tras varios días de intercambiar regalos y sin que Bligh soltara prenda del motivo de su visita, la ocasión se presentó sola cuando el nativo agradecía los bienes recibidos y manifestaba su adhesión al monarca británico.

- Usted, Tinah -preguntó el capitán-, ¿no querría también enviarle algo al rey Jorge?

- Sí - contestó-. Le enviaré todo lo que tengo.

Y empezó -sigue narrando Bligh-a enumerar diferentes artículos de lo que disponía, entre los cuales mentó el árbol del pan.

A mediados de diciembre ya estaban casi listos los plantones, cubiertos con una lona para evitar las salpicaduras del mal tiempo. Algunos estaban en estado latente y otros daban ya brotes nuevos. Era Nelson de opinión que tales plantas no se reproducian más que por las raices y, por tanto, di orden para llenar con ellas algunas cajas, que podríamos estibar en lugares que no servirian para las plantas (Figura 1).

En total embarcaron 774 tiestos con arbolitos, de los cuales una décima parte iba echando raíces: ninguno llegaría a las Antillas, pues ya de regreso, el 28 de abril de 1789, se produjo el famoso amotinamiento de Fletcher Christian. El capitán cuenta cómo fue embarcado en una chalupa, diciendo que, después de haber aguantado no pocas chanzas, y de servir algún tiempo de diversión a esos miserables, nos soltaron al garete en medio del océano. Dieciocho valientes se embarcaron con Bligh en la frágil embarcación, entre ellos el ahora "botánico" David Nelson, para emprender una heroica e increíble travesía de 47 días y más de 4.000 millas marítimas hasta Cupang, en las cercanías de Timor, donde desembarcaron y hallaron auxilio el 14 de junio de 1789. Como hemos relatado anteriormente Bligh era hombre versado en ciencias y así pudo aplicar varias medidas higiénicas a los tripulantes de la chalupa: embarcado en tan pequeño bote con un puñado de subordinados fieles y con escasísimos víveres, ordenaba a la mitad de su pequeña tripulación ponerse de pie por turnos, para hacer ejercicios; cuando llovía obligaba a todos a quitarse las ropas, meterlas al mar y luego retorcerlas hasta que pareciesen secas antes de volver a ponérselas. Además, como buen marino, en los momentos de mayor penuria les repartía dos cucharaditas de ron por cabeza. Así, sostuvo el capitán a su regreso, se mantuvieron saludables y sólo murió uno, pero a manos de nativos hostiles ${ }^{8}$.

\section{David Nelson, jardinero, botánico y zoólogo}

De este jardinero que, tras un breve cursillo, devino en "botánico" poco se sabe. No era pariente del Almirante heroico, pero su viaje en el Bounty y su regreso a Batavia en una chalupa sí lo fueron, y sobradamente. Se sabe que hasta 1776 trabajaba como jardinero en Kew Gardens, tarea que dejó por embarcarse como marinero al servicio de William Bayly, quien era "oficial astrónomo" a bordo del HMS Template. Pero en realidad ni era marinero ni ayudante del astrónomo: su verdadera misión nació de un acuerdo entre el capitán Cook y el botánico Banks, consistiendo en la recolección de especímenes para los jardines reales. Viajó, entonces, porque Cook no pudo encontrar un botánico dispuesto a hacer investigación

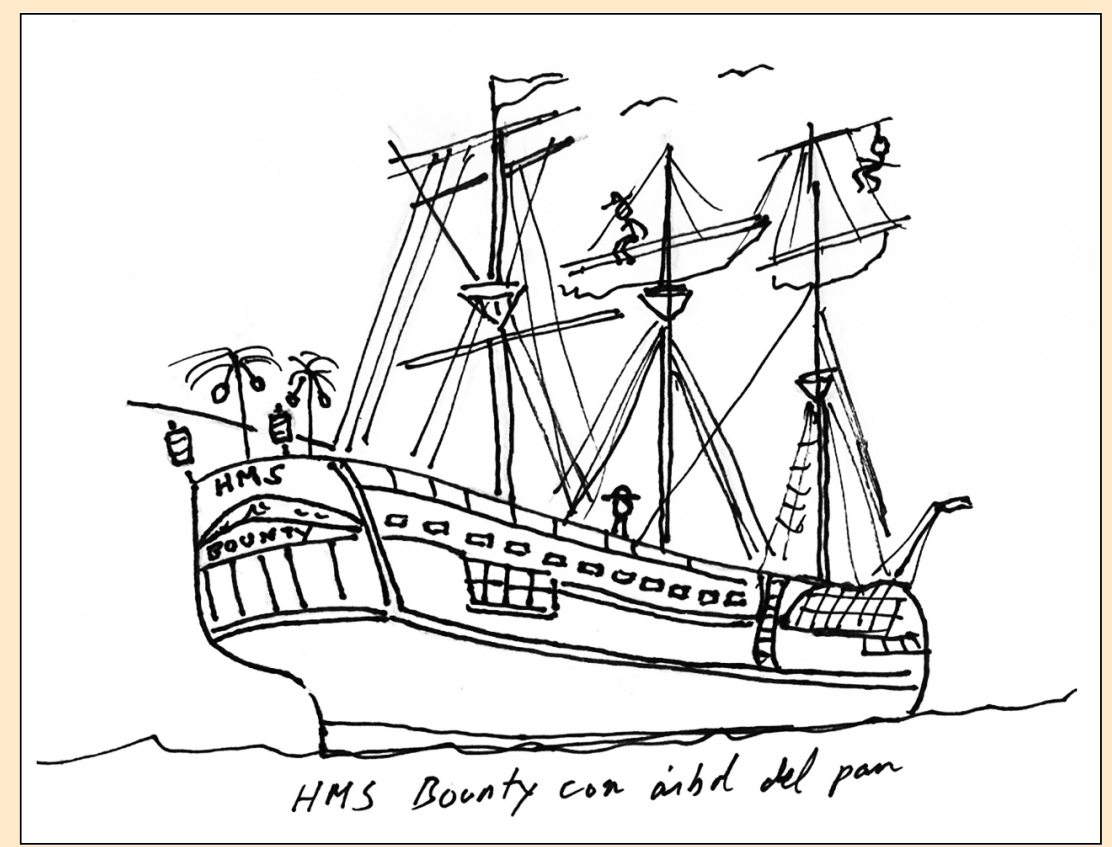

Figura 1. 
aventura por lejanos mares y peligrosas tierras, lo que demuestra que Nelson sí tenía esa disposición.

- Peor es mascar la hucha-dijo el capitán, al recibir la propuesta de Banks-. Lo acepto, pero usted encárguese primero de darle alguna instrucción en la materia, que para eso tiene a William Aiton, botánico capacitado y por ahora ocioso.

- De poco tiempo disponemos -replicó Banks, poniéndose de inmediato a la obra.

Que el hombre era inteligente y activo, respondiendo a su tarea más que adecuadamente, lo demuestra el que durante el viaje no sólo haya ejercido la botánica, sino también la zoología, al seleccionar una buena cantidad de aves nativas en Hawaii para el Museo Británico. ¿Las habrá llevado vivas o las habrá embalsamado?

Volviendo a Inglaterra retomó su cargo en Londres, el cuidado de los Kew Gardens, ejerciéndolo tranquilamente por siete años, hasta que Banks lo metió en la terrible aventura del Bounty. Ya en Tahití, Nelson hizo 1.015 almácigos del árbol del pan, de los cuales hemos visto como Bligh seleccionó los 774 que le parecieron en condiciones de aguantar el viaje de regreso, probando así el capitán que en verdad no carecía de cualidades para hacer ciencia.

El infortunio persiguió a David Nelson, tanto que, habiendo sobrevivido al motín y al increíble viaje en la chalupa de Tahití a Cupang, murió pocos días después. Historiadores sensacionalistas dicen que buscando hongos para el almuerzo eligió por error algunos venenosos, siendo su muerte cruelmente irónica para un botánico experto, pero Harold St. John, mucho más serio y más documentado, se limita a decir que "murió de una fiebre".

El capitán Bligh quiso honrar su memoria y bautizó como Mount Nelson a una montaña en Tasmania. Por su parte, algunos botánicos modernos, entusiasmados con sus aventuras, han puesto su nombre a dos especies, siendo la primera una planta africana, Tritonia nelsonii, descrita originalmente por John Gilbert Baker como Tritonia petrophila en 1892, y la segunda la Nolina nelsonii, planta mexicana descubierta en 1902 por Joseph Nelson Rose, quien no sabemos si era descendiente de nuestro aventurero jardinero londinense: en todo caso, no deja de ser una de esas increíbles coincidencias con que a menudo nos sorprende la historia de las ciencias $(9,10)$.

\section{El segundo viaje, con los HMS Providence y Assistance}

Al contrario de lo que dicen las películas norteamericanas y los fabuladores de siempre, Bligh no fue juzgado ni condenado por el motín del Bounty: sólo hubo una breve investigación sobre la pérdida del barco, no se le hicieron cargos, fue ascendido a capitán, prosiguiendo su carrera en la armada británica y en 1791 se le concedió una segunda oportunidad para completar su tarea. Poca información existía sobre este segundo viaje, opacado por los dramáticos incidentes del primero, pero a contar de $1920^{11}$ y aun más recientemente han surgido publicaciones al respecto, en todas las cuales basamos nuestro relato ${ }^{14,15}$.

Este segundo viaje de Bligh en busca del árbol del pan fue exitoso no sólo por haber cumplido su fin, sino también por una serie de hallazgos marítimos que facilitarían futuros viajes a esos lejanos viajes. Por decisión personal de un entusiasmado Rey Jorge la dirección de la empresa de traer el árbol del pan y explorar el estrecho de Torres, sito entre Australia y Samoa, se le encargó al experto Bligh, dotándole de dos navíos, los HMS Providence y Assistance, el primero de 420 toneladas, 98 pies de largo y tripulación de 110 hombres, y el segundo, más pequeñito, de sólo 110 toneladas, 51 pies y 27 hombres a cargo del teniente Nathaniel Portlock.

Como ya no estaba el pobre Nelson, el sempiterno promotor de la empresa, Sir Joseph Banks, destacó ahora a dos verdaderos botánicos James Wiles y Christopher Smith para seleccionar, cuidar y mimar a las plantitas, quienes además de procurar que llegaran vivas y sanas a Jamaica, debían llevar de éstos y de otros ejemplares muestras al Kew Gardens.

La expedición salió de Deptford el 22 de junio de 1791, los navíos pasaron a Galleons a armarse y embarcar al teniente Pearce, más un sargento, dos cabos, un tambor y quince marinos de la División Chatham, pues ya habían escarmentado de los ataques arteros de algunos nativos de esos lejanos mares, tras lo cual volvieron al puerto, ultimaron algunos detalles y salieron definitivamente el 12 de julio. Con la experiencia de su viaje anterior, Bligh no perdió el tiempo desafiando al Cabo de Hornos y se fue derechito al de Buena Esperanza rumbo a Tasmania, siguiendo la ruta del Bounty.

De Tasmania siguieron a Nueva Zelandia y descubrieron la isla de Tematangi, que pasó ipso facto a llamarse Bligh's Lagoon Island, quien la describiera como una "isla medio sumergida". No hubo incidentes y llegaron a Tahití, donde los nativos recibieron al capitán como un héroe y querido amigo, contándole el regreso de los amotinados y la captura de algunos por el Capitán Edwards, que de Christian y sus seguidores nunca más supieron.

Luego de tres meses salió hacia Tonga y las Fiji cargado de macetas con arbolitos del pan. En este viaje habría traído ejemplares del árbol que describiera y que terminara por llevar su nombre, Blighia sapida, que crece hasta doce meses, tiene frutos coloreados rojo magenta, de unos ocho centímetros de largo y también comestible, como el árbol del pan. Este descubrimiento botánico fue decisivo para que se le aceptara como fellow en la mítica Royal Society de Londres. 
Ahorramos a nuestros lectores la descripción que hace Ida Lee de las diversas islas visitadas hasta llegar al Estrecho de Torres, que Bligh, cumpliendo la orden del Rey, exploró al revés y al derecho, hasta encontrar la mejor vía de paso por un canal que hoy se llama, cómo no, Canal Bligh. De allí se fue a Timor y se tomó unos días de reposo en Cupang... ¿Algunos nostálgicos recuerdos de su famoso viaje en bote desde el Bounty?

Dejando Cupang, pasó el Cabo de Hornos hacia el Atlántico, fondeó el 17 de diciembre de 1792 en la tristemente célebre isla de Santa Helena, donde Napoleón penara sus últimos días, y le dejó algunos árboles del pan y otras plantas exóticas al Gobernador Broke, suponemos que por cortesía y a cambio de algunos víveres y agua, como se estilaba en esos viajes, para seguir luego hasta la isla de San Vicente, descubierta por Colón en su segundo viaje en 1498 y cedida a los ingleses en 1783, a donde arribó el 23 de enero de 1793: tras dos años de viaje, el árbol del pan había llegado a su destino en el Nuevo Mundo. Descargó Bligh sus plantitas y embarcó otras para los jardines de su monarca, siguiendo luego a Jamaica, donde llegó el 4 de febrero y dejó la mayor parte de los árboles, guardando unos poquitos para Inglaterra, dulce hogar que los victoriosos buques alcanzaron el 2 de agosto de 1793.

A los nativos de Jamaica el fruto no les gustó entonces, pues preferían el plátano; más, al pasar de los años, como la necesidad carece de leyes, necessitas caret lege ( y no "la necesidad tiene cara de hereje", como se suele decir), el árbol de Jack, yaca, o como quiera llamarse, se haría muy popular entre la población, especialmente entre los más pobres.

\section{¿Qué fue de los amotinados del Bounty?}

En 1808 el navío norteamericano Topaz encontró en la isla Pitcairn al último sobreviviente de los amotinados, Alexander Smith, quien ahora se hacía llamar John Adams, viviendo feliz con varias esposas nativas y numerosos niños. Por él se supo que los amotinados se habían dividido en dos grupos : los que no participaron del motín más otros que querían volver a Inglaterra, aun cuando hubieran de afrontar un juicio, y un puñado leal a Fletcher Christian, que decidió no retornar a la patria.

El primer grupo permaneció en Tahití hasta el arribo del HMS Pandora en 1791, que los embarcó hacia Inglaterra, a donde no alcanzó a llegar, pues naufragó antes. Los sobrevivientes, incluyendo gente de la tripulación y también prisioneros, se embarcaron en tres pequeños botes y en ellos llegaron a Timor, realizando una hazaña similar a la de Bligh pero sin mayor reconocimiento ni alharaca. Desde allí fueron a Inglaterra, donde ocho fueron juzgados y ahorcados tres.
El segundo grupo, compuesto por el citado Christian, ocho marineros ingleses, doce nativos y seis nativas, se embarcaron hasta encontrar, tras larga búsqueda, la remota y deshabitada isla Pitcairn, donde vararon la nave para luego incendiarla, de modo que no fuera visible desde el mar. Como era de suponer, pelearon por las mujeres, falleciendo primero los varones tahitianos y luego los ingleses, quedando solo Smith ${ }^{14}$. Creemos que la soledad, la lejanía de la patria y la familia, la imposibilidad de volver, terminaron por enloquecerlos.

\section{Una conclusión optimista}

Mirado en conjunto, el viaje del Bounty, planeado con las mejores intenciones, es una tragedia marítima digna de Esquilo, de la cual William Bligh terminó siendo el héroe vencedor. Las causas del motín no aparecen claras; los castigos con azotes eran pan de cada día en los HMS y Bligh no fue el más castigador; Fletcher Christian no había recibido sanción alguna que motivara su rebelión, confesando días antes a otro oficial: "estoy endemoniado, endemoniado". Si queremos un final feliz, consideremos que gracias al segundo viaje, con el Providence y el Assistance, el árbol del pan, multiplicado en todo el Caribe y tierras vecinas, cumplió con el objetivo de tener un alimento nutritivo, abundante y barato, con el cual incluso algunos chefs han confeccionado guisos exquisitos; y que Bligh, fallecido el 6 de diciembre de 1817, sepultado en Saint Mary's Lambeth, tiene una bella tumba en piedra de Coade (cerámica inglesa creada en esa época por Eleanor Coade), en cuya parte superior, a guisa de corona, hay una imagen de un árbol del pan, amén de un epitafio: "En memoria de William Bligh, célebre navegante que trasplantó por primera vez el árbol del pan desde Tahití a las Indias Occidentales". La iglesia en la actualidad es el Museo de la Historia del Jardín.

\section{Referencias bibliográficas}

1.- Éxodo 16: 14. En: La Santa Biblia. Antigua versión de Casiodoro de Reina (1569) revisada por Cipriano de Valera (1602). Sociedades Bíblicas de América Latina, Buenos Aires 1960.

2.- Números 11: 9. Ibid.

3.- Breadfruit. Collier's Encyclopedia. Crowell Collier and Mac Millan, Inc., 1967; 4: 515.

4.- Zarega N C Y, Ragne D, Motley T J. Systematics and species of breadfruit (Artocarpus, Moraceae). A Systematic Botany 2005; 30: 603-15.

5.- Sires R V, Bligh W. In : Collier's Encyclopedia, Crowell Collier and Mac Millan, Inc., 1967; 4: 254.

6.- The real Captain Bligh. http://www.chanel4.com/history/ microsites/R/real-lives.

7.- Ledermann W. Microbios abordan las naves de Su Majestad. Rev Chilena Infectol 1995; 22 (4): 371-6. 
8.- Bligh W. Viaje al mar del sur emprendido por orden de S.M. con el fin de transportar árboles del Pan a las Antillas en el bajel de S.M. la Bounty. Londres 1792. En: Mackaness G. Verdadera historia de la rebelión en la Bounty. Editorial Juventud S.A., Barcelona 1963; pp: 17178.

9- St. John Harold. Biography of David Nelson and an account of his botanizing in Hawaii. Pacific Science 1976; 30 (1): $1-5$.

10.- Edit History: Nelson, David ( -1789) on JSTOR https//plants.jstor.org/stable/history/10.555/al.ap.person. bm000055148.
11.- Ida Lee. (Mrs. Charles Bruce Marriott, F.R.G.S., HON F.R.A.H.S.) Captain Bligh's second voyage to the South Sea. With maps and illustrations. Longmans, Green and Co. 39 Paternoster Row, London, 1920.

12.- Andrew D. Bligh's successful breadfruit voyage. RSA Journal 1993; 141 (5444): 821-4.

13.- Bligh W, Oliver D L. Return to Tahiti: Bligh's second breadfruit voyage. Miegunvah Press series. Reimpresa y editada por Douglas L. Oliver. University of Hawaii Press 1988. Digitalizado 2 Dic 2006.

14.- Fuller E. Bounty mutiny. Collier's Encyclopedia. Crowell Collier and MacManus USA 1967; 4: 429-30. 